
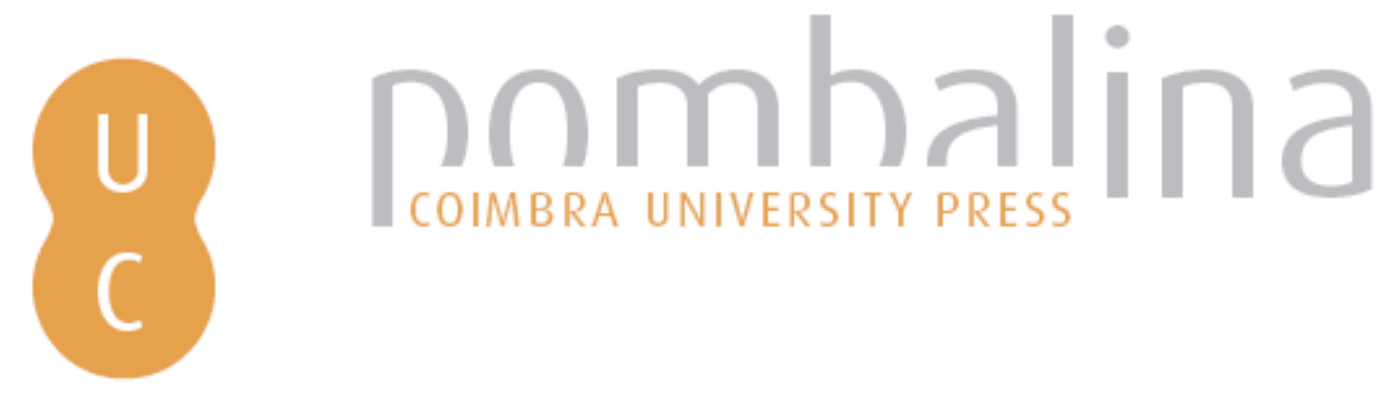

\title{
Representações sociais do abuso sexual de crianças numa amostra de médicos e enfermeiros dos cuidados de saúde primários
}
Autor(es):
Fazenda, Isabel
Publicado por: Imprensa da Universidade de Coimbra
URL
persistente:
URI:http://hdl.handle.net/10316.2/36634
DOI:
DOI:http://dx.doi.org/10.14195/978-989-26-0968-3_5
Accessed : $\quad$ 26-Apr-2023 01:12:52

A navegação consulta e descarregamento dos títulos inseridos nas Bibliotecas Digitais UC Digitalis, UC Pombalina e UC Impactum, pressupõem a aceitação plena e sem reservas dos Termos e Condições de Uso destas Bibliotecas Digitais, disponíveis em https://digitalis.uc.pt/pt-pt/termos.

Conforme exposto nos referidos Termos e Condições de Uso, o descarregamento de títulos de acesso restrito requer uma licença válida de autorização devendo o utilizador aceder ao(s) documento(s) a partir de um endereço de IP da instituição detentora da supramencionada licença.

Ao utilizador é apenas permitido o descarregamento para uso pessoal, pelo que o emprego do(s) título(s) descarregado(s) para outro fim, designadamente comercial, carece de autorização do respetivo autor ou editor da obra.

Na medida em que todas as obras da UC Digitalis se encontram protegidas pelo Código do Direito de Autor e Direitos Conexos e demais legislação aplicável, toda a cópia, parcial ou total, deste documento, nos casos em que é legalmente admitida, deverá conter ou fazer-se acompanhar por este aviso.

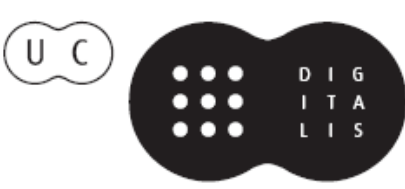




\section{CADERNOS DE PSIOUIATRIA SOCIAL E CULTURAL}

\section{\# 0}

MANUEL JOÃO QUARTILHO (COORD.)

HELDER ALMEIDA

ISABEL FAZENDA

ISABEL GIL

LINDA FERNANDES

MARIA DE FÁTIMA SOUSA

NUNO CARRILHO

RITA ALCAIRE

IMPRENSA DA UNIVERSIDADE DE COIMBRA COIMBRA UNIVERSITY PRESS 


\section{Representações sociais do abuso sexual de crianças numa amostra de médicos e enfermeiros dos cuidados de saúde primários}




\section{Isabel Fazenda ${ }^{23}$}

\section{Resumo}

O abuso sexual de crianças é uma realidade global e incontornável nos nossos dias constituindo pelas suas múltiplas dimensões um especial desafio para um vasto leque de profissionais.

Pretendeu-se com este trabalho identificar as Representações Sociais em torno do Abuso Sexual de Crianças numa amostra de médicos e de enfermeiros dos Cuidados de Saúde Primários por se considerar que estes profissionais constituem frequentemente a primeira e única "porta de entrada" de silêncios implícitos na abordagem deste problema. Procurou conhecer-se a influência que essas representações poderão ter nas dinâmicas de prevenção e de intervenção daqueles profissionais, e criar instrumentos de avaliação das representações sociais em torno da temática.

Trata-se de um estudo empírico efetuado numa amostra de médicos e de enfermeiros dos Cuidados de Saúde Primários. Foram utilizados três questionários de auto-resposta com o objetivo de identificar a legitimação/aceitação do abuso sexual de crianças (Questionário de Representações sobre Abuso Sexual de Crianças - Histórias- QRASC-HIS), bem como os fatores facilitadores/ desencadeadores da ocorrência de abuso sexual de crianças, os fatores responsáveis pela manutenção e os que permitem interromper estas relações abusivas (Questionário sobre Abuso Sexual de Crianças - Facilitadores, Manutenção e Resolução- QASCFMR) e ainda a legitimação do comportamento sexualmente abusivo, a partir de um conjunto de afirmações em relação a situações de abuso sexual de crianças (Escala de Crenças sobre Abuso Sexual- ECAS).

A amostra constitui-se por 153 profissionais, 76 médicos e 77 enfermeiros dos Cuidados de Saúde Primários.

Para avaliar a validade empírica, do QRASC-HIS recorreu-se à análise fatorial exploratória, a partir desta análise identificaram-se cinco fatores que no seu conjunto explicam $67 \%$ da variância, e a estrutura fatorial obtida aproximou-se das dimensões teóricas prévias à construção do questionário. No QASCFMR o valor mais alto de concordância nos fatores de ativação foi de $65,3 \%$, nos fatores de manutenção de $83,7 \%$, e nos fatores de resolução foi de $84,7 \%$.

Foram analisadas as influências relativas à idade, existência de filhos, estado civil, habilitações académicas, categoria profissional, local de trabalho, experiência profissional, formação específica na área do abuso sexual e contacto prévio com situações de abuso sexual de crianças.

Conclusões - os instrumentos utilizados apresentam boas qualidades psicométricas a nível da consistência interna.

Os médicos e os enfermeiros dos Cuidados de Saúde Primários evidenciaram muito baixa tolerância ao abuso sexual de crianças. 
Relativamente à avaliação dos fatores promotores, de manutenção e de resolução os que apresentaram maior concordância foram respetivamente os "antecedentes de violência na família do abusador", e "as ameaças por parte do abusador"; "informar a população em geral sobre a problemática do abuso sexual de crianças"; e "dar apoio à vítima para que ela adquira competências de impedir o abuso". Estes resultados são consonantes com a literatura.

Da análise da influência das variáveis independentes constatou-se que o sexo, a idade, a categoria profissional e o tempo de serviço da profissão apresentam uma influência estatisticamente significativa na perceção do abuso sexual de crianças.

Palavras-chave: Abuso Sexual de Crianças; Representações Sociais; Fatores de Ativação; Fatores de Manutenção; Fatores de Resolução; Médicos e Enfermeiros dos Cuidados de Saúde Primários.

\section{Abstract}

Children sexual abuse is nowadays a global and real fact being by their multiple dimensions a special challenge to a vast group of professionals.

With this dissertation we aimed to identify the social representation about the sexual abuse of children in a range of Primary Health Care professionals. These professionals are frequently the first and the unique "principal door" of implicit silences in the broach of this problem. With this research we aimed to infer how this social representations can influence the dynamics of prevention and intervention of these professionals, and create evaluation measurements of the social set of beliefs around the sexual abuse of children. We did the context of this set of questions, and pointed out some important fields of the children sexual abuses study: concept(s), socio-historical, juridical-legal, scientific evolution and explanatory models. We present an empirical study carried whith a sample of medical doctors and nurses of the Primary Health Care. In this study we used three auto-reply questionnaires, which aim to understand the legitimacy of the Children sexual abuse (Questionnaire of Beliefs on Children Sexual Abuse-Histories), as well as the promotional factors which lead to the sexual abuse of children, the responsible of its maintenance, the factors which cease or interrupts these abusive relations (Questionnaire on Sexual Abuse of Children Factors, Maintenance and Resolution) and also the legitimacy of the sexually abusive behaviour from a set of statements related situations of sexual abuse (Scale of Beliefs on Sexual Abuse).

Our range includes 153 heath professionals, 76 medical doctors and 77 nurses of the Primary Health Care.

To analyse the empirical validity of QRASC-HIS we used the exploratory factor analysis, and with this analysis we identified five factors that explained $67 \%$ of variance, and obtained a factor structure near the theoretical previous ideas.

In the QASCFMR the higher value of agreement was 69,3\% in promotional factors, 83,7\% in maintenance factors, and $84,7 \%$ in resolution factors. 
We analyse the influences of age, having children, marital status, the academical competences, and professional category, as well as the place of work, and the professional experience, and specific training on the issue of this study, and also previous contacts whith sexual abuse of children situations.

Conclusions - The evaluation instruments have good psychometric qualities in the level of internal consistency, in the QRASC-HIS we obttained to the total scale a coefficient value of a Cronbach alph coefficient value of a Cronbach alpha .951. In the QASCFMR we obtained to the push factor an alpha coefficient of .893, to the maintenance factor .925, and to the resolution factor .944 . In the ECAS we obtained a coefficient value of .898

Medical doctors and nurses from Primary Heath Care show a very low tolerance to the sexual abuse of children. Regarding the evaluation of push factors, maintenance and resolution factors of the sexual abuse of children, the results who obtained an higher level of agreement was "previous violence in the perpetrator family" "perpetrator threats"

"Inform the public about children sexual abuse" and "suport the victim to get competence to hold the abuse" . The results prove to be in line with the literature.

With regard to the independent variables the results revealed that sex, age, professional category and lengt of service affect the perception of these professionals about the sexual abuse of chilren.

Keywords: Children Sexual Abuse; Social Representations; Promotional Factors; Maintenance Factors; Resolution Factors; Medical Doctors and Nurses of the Primary Health Care. 
Falar de Abuso Sexual é falar de maus-tratos, na sua forma mais carnal e sentida, com toda a certeza. Neste jaez, a vítima do abusador sexual é ofendida no seu supremo direito à integridade física e moral, vê comprometido o seu direito a um integral desenvolvimento físico, afectivo e social (direito à alegria de viver os "verdes anos" sem atropelos impostos, sem vivências sexuais precoces não consentidas), vê-se impedida no seu absoluto direito de viver como criança o tempo de ser criança, sem "comer etapas à vida" e sem responsabilidades, remorsos ou culpabilidades prematuras...

Paulo Guerra (2006, p.43)

\section{Introdução24}

O abuso sexual de crianças coloca-nos de imediato o desafio de operacionalização do conceito, pois sobre a definição de abusos sexuais de crianças há apenas um consenso: o de que não há consenso (Fávero, 2003; Finkelhor, 1986; López, 1995). Como salienta Alberto (2006) uma definição objetiva levanta questões de unanimidade e universalidade que, conforme referem Lawson (1993) e Konker (1992) são fortemente influenciadas pelos contextos sócio culturais. Conforme defende López (1995) o abuso sexual deve ser definido a partir de dois grandes conceitos, a coerção e a assimetria de idade. Considera-se que há abuso sexual de crianças "nos contactos e interacções entre uma criança e um adulto, quando o adulto usa a criança para se estimular sexualmente, mesmo que para tal não chegue a estabelecer contacto corporal" (National Center of Child Abuse and Neglet - NCCAN, 1978). O abuso ocorre então quando "um sujeito em condições de superioridade (idade, força, posição social ou económica, inteligência, autoridade) comete um acto ou omissão capaz de causar dano físico, psicológico ou sexual, contrariamente à vontade da vítima ou por consentimento obtido a partir de indução ou sedução enganosa" (Pires, 2005: 44).

Sintetizando, Alberto (2006) refere que o abuso sexual configura qualquer experiência sexual com ou sem o recurso à força que pode oscilar num espectro entre formas passivas, como a exibição de pornografia, ou a utilização da criança para produção de pornografia infantil até à relação sexual (genital, anal ou oral) podendo de imediato ou a longo prazo provocar graves perturbações no desenvolvimento da criança.

Numa perspetiva histórica a "violência exercida sobre a criança, ao longo dos tempos, confunde-se com a história da própria humanidade" (Canha, 2000: 17). O conceito de infância foi um conceito incógnito ao longo dos séculos. A concepção de infância como uma etapa sem especificidades e de reduzido interesse estava associada a importantes factores sociais, contribuindo para um ambiente pouco adequado para a criança. A infância moderna, associada às imagens românticas da criança-mimo, a criança-gozo, a criança-fragilidade, a criança centro do mundo familiar, é uma construção social recente e produto de um certo tempo histórico (Almeida, 2001).

24 Texto realizado com base na Tese de Mestrado com o mesmo nome no âmbito do I Mestrado em Psiquiatria Cultural da Faculdade de Medicina, orientada pela Professora Doutora Jeni Canha e coorientada pela Professora Doutora Isabel Alberto. 
No que concerne ao abuso sexual, a dominância de uma atitude sexofóbica que durante séculos predominou em todo o mundo contribuiu para desvalorizar a importância e a frequência dos abusos sexuais a crianças (López, 1995). A abordagem da história do abuso sexual de crianças implica a compreensão do funcionamento familiar, do valor social da infância e dos comportamentos sexuais ao longo dos tempos (Fávero, 2003), daí a pertinência de analisar as representações sociais partilhadas num dado contexto social e histórico.

Numa perspetiva científica mais do que a tomada de consciência e sensibilização para a temática do abuso sexual de crianças, temo-nos deparado nas últimas décadas com a construção de novas representações sobre a problemática. O emergir de algumas destas representações decorre da elaboração de um conjunto de saberes das várias áreas científicas que se debruçam sobre a infância. Se, por um lado, estas novas conceções resultam de estudos específicos, por outro, não deixam de receber a influência das convicções subjetivas e discursos socioculturais da comunidade geral e dos diversos grupos profissionais.

De igual modo a perspetiva jurídico-legal do Abuso Sexual de Crianças sofreu, ao longo do tempo, profundas transformações na forma de ser entendido, com o Direito a tentar, na sua essência, adequar-se ao enquadramento social e cultural envolvente. A evolução tecnológica com, entre outros, o aparecimento de um cada vez maior número de sites de pornografia infantil, veio obrigar o legislador a adequar intervenções em novas formas de criminalidade. Através do código penal (ver artigos $171 .^{\circ}$, 172. ${ }^{\circ}, 173 .^{\circ}, 174 .^{\circ}, 175 .^{\circ}$ e $176 .^{\circ}$ ) de 2007 (Almeida, \& Vilalonga 2007) Portugal procura contemplar as necessidades de proteção à criança nesta temática.

No olhar de Carmo, Alberto e Guerra (2006) as situações de abuso sexual de crianças são para a Justiça de menores as que mais apreensões trazem aos aplicadores da lei pelas inibições que envolvem a vítima, o agressor e o sistema familiar no seu todo, revelando a importância de um aumento do conhecimento sobre o abuso sexual, que providencie a correta análise de cada situação e evite a interpretação dos factos à luz do rótulo de abuso sexual. Como salienta Alberto (2006: 77) "a perspetiva legal do abuso parece alertada para a necessidade de conjugação com a intervenção psicoterapeuta e social em todos os elementos do sistema familiar". Constituir-se-á, no entanto, de capital importância, um efetivo esforço na aplicação destes princípios, com vista a que a intervenção não possa vir a constituir como refere Furniss (1993) "um des-serviço" para a criança.

No decorrer das últimas décadas, várias foram as investigações levadas a cabo na procura de abordagens explicativas do abuso sexual de crianças. As explicações avançadas tendem a centrar-se na caracterização dos abusadores consoante as estratégias de abuso, o perfil da vítima, e os processos subjacentes à construção e manutenção do Síndrome do Segredo.

O conhecimento teórico atual sustenta a noção que a agressão sexual é um fenómeno multideterminado, resultando da congruência de fatores "disposicionais, cognitivos, situacionais e culturais" (Machado, 2010: 73).

\section{Representações Sociais em torno do Abuso Sexual de Crianças}

O conceito de representação social filia-se no conceito de representação coletiva introduzida por Durkheim e retomada por Moscovici em 1961. De acordo com o próprio Moscovici, a representação 
social refere um conjunto de conceitos, proposições e explicações, criado no quotidiano, no decurso da comunicação, integrando os mitos e os sistemas de crenças das sociedades tradicionais, podendo ser vistas como uma versão atual do senso comum, (Moscovici,1961) relevando as dimensões do conhecimento que não partem apenas de teorias científicas, mas de eixos culturais e experiências quotidianas.

As representações sociais assumem um papel fulcral na violência, quer por definirem as normas sociais pelas quais a sociedade se pauta, quer por modelarem o entendimento que as sociedades constroem acerca das experiências (Machado et al., 2006), constituindo-se impossível compreender a violência sem intentar perceber os verdadeiros conteúdos das representações sociais (Porto, 2006). Na problemática do abuso sexual de crianças a compreensão ecológica e dinâmica do abuso espelha as conceções sociais dominantes em relação ao fenómeno relevando a importância de se estabelecerem estratégias de prevenção e intervenção que tenham em consideração os diferentes níveis: individual, social e cultural. A dimensão cultural integra as representações sociais que numa comunidade se vão constituindo sobre o que é aceite e tolerado e o que é inadequado e inaceitável.

A atribuição do abuso sexual de crianças às características do abusador conduz indubitavelmente ao conceito de "erro fundamental" que consiste na propensão de sobrestimar predisposições pessoais, traços de personalidade, em detrimento da circunstância nas nossas explicações do comportamento (Leyens, 1985). O "erro fundamental" tem origem nas Teorias Implícitas da Personalidade enquanto "crenças gerais que alimentamos a propósito da espécie humana, no que concerne à frequência e variabilidade de um traço de carácter na população" (Leyens, 1985, p.31).

Nesta perspetiva, as representações sociais dos médicos e dos enfermeiros dos CSP, a quem compete conhecer mitos e crenças relacionados com a sexualidade e com o abuso sexual de crianças, resultarão das suas construções realizadas enquanto indivíduo mas também enquanto profissionais de saúde.

Apesar da afirmação de Furniss (1993: 13) "enquanto um "pouquinho de violência' é aceitável", um "pouquinho de sexo' não é", continua-se a verificar que a intolerância perante a temática do abuso sexual não se traduz numa maior e mais efetiva proteção das crianças. Para além do dever ético, legal e moral, os profissionais dos CSP devem perceber a importância da sua intervenção na prevenção ou interrupção do abuso sexual da criança e ultrapassar, entre outros, a sua ainda notória relutância em denunciar. Importa fazer algo pela "real preservação da saúde, segurança, formação, educação e desenvolvimento destas crianças ou jovens que se veem envolvidos nestas teias de desamor e nojo, com que, tantas vezes, se veste o respeito e a obediência aos mais fortes e àqueles cuja primeira tarefa deveria ser antes a de proteção!" (Carmo, Alberto \& Guerra, 2006: 65).

Assumindo então a representação acerca de um fenómeno como parte parte construtiva do mesmo, "criando-o" de certa forma (Porto, 2006), revela-se fundamental considerar este fator quando se estuda o fenómeno do abuso sexual de crianças, identificando os discursos sociais mais comuns em profissionais como os médicos e enfermeiros dos cuidados de saúde primários, um grupo com uma relevância específica na proteção da criança.

A componente empírica deste trabalho, teve como objetivo geral identificar as representações sociais destes profissionais em torno do abuso sexual de crianças, e criar uma medida de avaliação das 
representações sociais em torno desta temática, e como objetivos específicos: identificar as características do Abuso Sexual de Crianças mais suscetíveis de serem consideradas abusivas pelos médicos e enfermeiros dos Cuidados de Saúde Primários; determinar as atribuições que estes profissionais têm sobre os fatores facilitadores, de manutenção e de resolução do abuso sexual de crianças; validar o Questionário de Representações sobre o abuso sexual de crianças-Histórias (QRASC-HIS) e o Questionário sobre abuso sexual de crianças-Fatores Facilitadores, Manutenção e Resolução (QASCFMR) com uma amostra de médicos e enfermeiros dos CSP; e ao mesmo tempo analisar a influência de algumas variáveis sócio-demográficas da amostra em estudo nas respostas aos instrumentos utilizados.

\section{Metodologia}

A recolha de dados foi realizada de acordo com um processo de amostragem não aleatória, de conveniência. Os potenciais sujeitos, médicos e enfermeiros dos Cuidados de Saúde Primários, foram abordados através de contactos pessoais, quer no local de trabalho, quer em reuniões e eventos científicos. Dos questionários distribuídos e recolhidos obteve-se uma amostra constituída por 153 sujeitos, dos quais 76 são médicos, e 77 são enfermeiros. No que concerne ao sexo, a amostra incluiu 33 indivíduos do sexo masculino e 120 indivíduos (78,4\%) do sexo feminino. A idade mínima dos sujeitos é de 24 anos e a idade de máxima 65 anos, situando-se a média de idade nos 44 anos. Relativamente ao estado civil, a amostra compôs-se maioritariamente de sujeitos casados 104, correspondente a $68 \%$ da amostra, 27 solteiros, 18 divorciados, e 4 viúvos. Dos sujeitos que compõem a amostra 120 (78,4\%) têm filhos, e 33 não têm. Relativamente às habilitações académicas dos participantes, a maioria, 143 (93,5\%) são licenciados, 9 concluíram um mestrado, e 1 concluiu doutoramento. Dos 153 inquiridos, 68 trabalham em centros de saúde de área rural, 44 trabalham em centros de saúde de área medianamente urbana, e 41 em centros de saúde de área urbana.

Relativamente à experiência profissional-tempo de serviço, a amostra variou entre 0 e 40 anos, sendo a média 19,95 anos, correspondente a um desvio-padrão de 10,02. No que concerne à experiência profissional, em termos de contacto prévio com casos de crianças vítimas de abuso sexual 86 sujeitos revelaram uma resposta negativa, enquanto 67 sujeitos confirmaram já ter tido esse contacto. Aos sujeitos da amostra foi questionado a que entidade comunicariam caso suspeitassem da ocorrência de Abuso Sexual de Crianças, e o resultado revelou que 38 sujeitos comunicariam à CPCJ, 14 referenciariam à assistência social, 10 ao diretor do centro de saúde, 9 ao coordenador de saúde infantil e juvenil do centro de saúde, 9 avisaria a Polícia / G.N.R., 66 dos sujeitos optariam por comunicar simultaneamente a várias entidades, e 1 comunicaria à Policia Judiciária. Relativamente à perceção sobre a informação/formação que detêm para identificar uma situação de suspeita de ASC, 71 sujeitos consideram ser "satisfatória", 57 refere que é "insuficiente", 24 afirma ser "boa", e apenas 1 descreve ser "muito boa". Em relação à forma como percecionam a sua informação/formação para atuar numa situação de suspeita de Abuso Sexual de Crianças, 66 sujeitos revelam ter formação "insuficiente", 65 diz possuir uma formação "satisfatória", 21 perceciona-a como "boa" e apenas 1 referiu considerar ser "muito boa". No respeitante às fontes de informação/formação a que os sujeitos da nossa amostra recorreram, 25 referiram ter sido 
através de leituras alusivas ao tema, 10 sujeitos acederam a informação através da comunicação social, 6 referem ter tido ações de formação, 3 recorreram a pesquisa informática, 2 estiveram presentes em congressos, 2 recorreram a outras fontes e 105 sujeitos referiram que a informação/formação provieram da conjugação de várias fontes.

\section{Instrumentos de pesquisa utilizados}

a) Questionário de Representações sobre Abuso Sexual de Crianças- Histórias (QRASC-HIS) (Alberto, Alarcão, Fazenda, \& Querido, 2008);

b) Questionário sobre Abuso Sexual de Crianças - Fatores Facilitadores, Manutenção e Resolução (QASCFMR) (Alberto, Alarcão, Querido, \& Fazenda, 2008);

c) Escala de Crenças sobre Abuso Sexual (ECAS) (Machado, Gonçalves, \& Matos, 2000);

d) Questionário sócio demográfico de recolha de dados.

\section{Apresentação dos Resulttados}

Variáveis sócio demográficas e representações sociais em torno do abuso sexual de crianças

Considerando as variáveis "estado civil", "existência de filhos", "área do centro de saúde" onde exerce a profissão, "qualidade de informação para atuação em casos de ASC", "qualidade de informação para identificação de ASC", bem como " fontes de informação" sobre a temática, "experiência profissional com crianças vítimas de Abuso Sexual de Crianças", e "a quem comunicaria a suspeita de um caso de Abuso Sexual de Crianças", não se obtiveram diferenças estatisticamente significativas nas respostas dos inquiridos aos diversos instrumentos.

A variável "habilitações académicas" não foi analisada, considerando que a maioria dos sujeitos tem licenciatura, havendo apenas um sujeito com doutoramento e 9 com mestrado.

Na análise da influência da variável "sexo" as médias indicaram que os indivíduos do sexo masculino apresentam valores mais legitimadores do abuso sexual de crianças.

No que concerne à análise da influência da variável "categoria profissional", observaram-se diferenças estatisticamente significativas nas respostas dadas com os médicos a apresentarem valores mais legitimadores que os enfermeiros.

Em relação à influência da variável "experiência profissional em tempo de serviço" e transformando a variável em categorias integrando na categoria 1 (até 10 anos), 2 (de 11 a 20 anos), 3 (entre 21 e 30 anos) e 4 (entre 31 e 40 anos de serviço), registaram-se diferenças estatisticamente significativas. Verificando-se que a progressão na carreira em tempo de serviço se acompanha de um aumento da legitimação.

No que concerne à variável "idade", codificada por categorias, 1, (24-30) anos; 2, (31-40); 3, (41-50); e 4, (51-64) anos, obtiveram-se diferenças estatisticamente significativas. Constatou-se que a idade influencia a legitimação, tendo os respondentes de idades mais avançadas legitimado consideravelmente mais.

Analisando a influência da idade separadamente para o sexo masculino e para o sexo feminino, verificou-se a existência de diferenças significativas no sexo masculino-idade. Os homens entre os 41 e os 50 anos surgem como os que menos legitimam o abuso sexual de crianças. 
Em relação ao sexo feminino-idade verifica-se a existência de diferenças significativas nas respostas dadas com as médicas e enfermeiras, com mais idade entre os 51 e os 64 anos a legitimarem mais a situação abusiva.

Considerando a variável idade para cada uma das profissões, médicos e enfermeiros, não se encontraram diferenças estatisticamente significativas

\section{Questionário sobre Abuso Sexual de Crianças - Fatores Facilitadores, de Manutenção e Resolução}

Analisaram-se as respostas dos sujeitos da amostra a partir do seu grau de concordância com os itens que compõem a escala, sendo que para cada conjunto de fatores existem condições da criança/ vítima, condições do abusador e condições externas.

Considerando os fatores facilitadores do abuso sexual de crianças, o fator com o qual os sujeitos apresentaram maior concordância correspondeu a "antecedentes de violência na família de origem do abusador", secundado pelo fator "o abusador ter sido ele próprio vítima de abuso sexual quando criança ou adolescente".

As características habitacionais que favorecem a promiscuidade surgiram também como relevantes.

Analisando as causas que obtiveram menor concordância, o comportamento provocador da vítima registou 77,1\% de respostas discordantes. Os respondentes discordam igualmente que a falta de atenção para com o abusador por parte do cônjuge, os problemas conjugais do abusador, e o baixo grau de instrução deste sejam condições predisponentes para o abuso sexual de crianças. Importa ainda referir que a deficiência mental e/ou física da vítima e o isolamento social da família da vítima surgem com um grau de concordância/discordância muito equivalente, constatando-se assim uma divergência na opinião dos sujeitos da amostra.

Relativamente aos fatores que contribuem para a manutenção das relações sexualmente abusivas, as respostas são tendencialmente concordantes com os itens que compõem a escala. Destacando-se, as ameaças por parte do abusador com 83,7\% de concordância, seguida da ausência de denúncia por parte da vítima ou da família. Ainda com um elevado grau de concordância surge o medo da vítima de ficar rotulada como "alguém que foi sexualmente abusado", e o receio da vítima de ser sujeita a várias avaliações e depoimentos.

A ausência de denúncia por parte dos profissionais surge com a maior percentagem de discordância $(46,4 \%)$.

No que concerne aos fatores de resolução do abuso sexual de crianças, as respostas foram tendencialmente concordantes com os itens que compõem este fator. De notar que os itens considerados de maior importância para resolver as situações abusivas foram "informar a população em geral sobre a problemática do abuso sexual de crianças", com a mesma percentagem do item "dar apoio à vítima para que ela adquira competências para impedir o abuso".

Ainda com elevada percentagem de concordância (83\%) surge o item "tornar os procedimentos nos Tribunais mais rápidos e menos dolorosos".

Relacionado com o anterior, confirmou-se o fator "estimular a denúncia das situações de abuso sexual" $(82,4 \%)$ seguido de "validar, no dia a dia, os direitos das crianças". 
Os itens considerados como menos relevantes para pôr fim às relações sexualmente abusivas pelos sujeitos deste estudo são "mudar o comportamento da vítima para ser menos provocadora".

\section{Discussão}

Da análise descritiva dos resultados obtidos no Questionário de Representações sobre Abuso Sexual de Crianças-Histórias e na Escala de Crenças sobre Abuso Sexual, registou-se conforme expectável que os médicos e enfermeiros dos CSP apresentam valores pouco legitimadores do abuso sexual de crianças. Comparando a média de respostas à ECAS com o estudo de Querido (2009) numa amostra de educadores de infância a diferença não mostrou ser significativa. A semelhança nos resultados em relação à pouca legitimação do abuso sexual de crianças poder-se-á atribuir ao facto de ambas as amostras serem constituídas por populações privilegiadas no contacto com crianças, expetavelmente detentoras de informação e sensibilização relativamente ao fenómeno.

Ao analisar as respostas ao QRASC-HIS verificou-se que a História C é aquela onde existe uma maior legitimação do abuso sexual de crianças. A História $C$ remete para o abuso perpetrado pelo progenitor do sexo feminino, assim, sendo sustentado pela nossa sociedade o estereótipo de que a mulher, principalmente as mães são, em essência carinhosas e protetoras (Fávero,2003). Os resultados revelaram-se congruentes com o discurso social, e denotam que estes profissionais ainda não superaram falsas crenças sobre o sexo do agressor no abuso sexual de crianças. Demonstram ainda refletir o que a literatura avança sobre o abuso sexual de crianças por mulheres ao referir, que este comportamento não se enquadra no conjunto de comportamentos previstos nos esquemas sociais (Furniss, 1993; Salter, 1988). A sociedade atual evidencia uma maior aceitação social do contacto corporal entre mulheres e crianças, como não abusivo, revestido de uma conotação de "normal" ternura maternal e não de um cariz sexual (Carmo, Alberto, \& Guerra 2006).

Ainda na análise dos resultados referentes à História $C$, ao remeter para o abuso de uma criança de quatro anos, do sexo masculino, cuja mãe é enfermeira, deverá ser tido em conta a possibilidade de espelharem a permeabilidade do discurso destes profissionais ao discursos sociais simplistas e desajustados de que o abuso ocorre exclusivamente em crianças do sexo feminino, de que as crianças muito pequenas não são abusadas, e, ainda ao invés do demonstrado pelos estudos, a crença de que os agressores sexuais apresentam uma baixa competência social (Finkelhor, 1994; Machado, 2002).

A História A foi aquela em que emergiu uma menor legitimação do abuso sexual de crianças. Tratando esta história do abuso perpetrado por um idoso à neta, uma menina de cinco anos, poderá espelhar a formação destes profissionais nesta temática, em relação ao perfil do abusador ser transversal a todas as idades, bem como evidenciar a sua perceção de que, tal como demonstrado em diversos estudos, o abuso é frequentemente intrafamiliar (Furniss, 1993; López, 1995). Poderá ainda refletir a influência nestes profissionais da informação veiculada pelos media, reportando inúmeros casos em que o abusador revelou ser um idoso "insuspeitável".

Atendendo a que o QASCFMR avalia os fatores facilitadores, de manutenção, e de resolução, analisaram-se aqueles que reuniram maior e menor concordância nas respostas destes profissionais. 
No que concerne às condições facilitadoras, e, relativamente ao fator em que os sujeitos manifestaram maior concordância, "antecedentes de violência na família do abusador", diversos estudos suportam a associação entre crescer em ambientes violentos e ser um adulto violento, quer seja como vítima quer como agressor (Walker,1984), constituindo assim um resultado expectável e congruente com o descrito na literatura sobre transmissão geracional da violência corroborando que crianças que crescem em meios onde imperam dinâmicas violentas tenderão, quer no presente quer no futuro, a mimetiza-las como forma de resolução dos seus conflitos. Relativamente ao segundo fator, "o abusador ter sido ele próprio vítima de abuso sexual quando criança ou adolescente" a investigação tem sustentado que os indivíduos expostos a abuso sexual em crianças têm grande probabilidade de poderem tornar-se abusadores (López, 1995: Furniss, 1993). Todavia, os mesmos autores destacam que nem todas as vítimas virão necessariamente a ser agressores sexuais, dependendo da influência de outras condições, como o suporte recebido no momento da revelação, ou uma intervenção terapêutica adequada que encoraje a superação da vivência abusiva. Autores como Finkelhor (1979) e Furniss (1993) relembram que a maioria das vítimas é do sexo feminino enquanto a maioria dos agressores é do sexo masculino, destacando o papel fundamental da educação e da construção de identidade de género, ou seja, o importante contributo de fatores culturais.

Relativamente às "características habitacionais que favorecem a promiscuidade" notamos que uma elevada percentagem destes médicos e enfermeiros, profissionalmente próximos dos contextos familiares e sociais, consideram ser relevante no espoletar das situações abusivas, por oposição à opinião de autores como Azevedo e Guerra (1993) que desconstroem a falsa ideia de que o abuso é próprio de meios marginalizados da sociedade, e sustentam que o abuso sexual de crianças é extremamente democrático sendo transversal a todas as classes sociais e níveis socioeconómicos e culturais.

A deficiência mental e/ou física da vítima mostrou uma divergência de opiniões nestes médicos e enfermeiros. Sendo profissionais que lidam frequentemente com a deficiência nas suas múltiplas dimensões, o resultado pode estar relacionado com diferentes correntes de formação/informação e/ ou sensibilização neste campo em particular. Trata-se no entanto de um aspeto que interessará ser alvo de reflexão em futuras investigações.

O comportamento provocador da vítima sendo o fator promotor com que estes profissionais demonstraram maior discordância, é um resultado expectável que sugere formação/informação específica e denota que o estereótipo da "criança sedutora" tendente a desresponsabilizar o agressor (Furniss, 1993) e fomentar a culpabilidade da criança (López, 1995), não se inscreve no discurso destes profissionais.

Relativamente às condições que contribuem para a manutenção das situações abusivas a análise dos resultados obtidos demonstra serem sobreponíveis ao plasmado no corpo literário existente sobre a temática e parecem estar interrelacionados. Segundo alguns autores (Fávero, 2003; Mckenna, 2005), as ameaças por parte do agressor, aliadas ao medo da estigmatização, conjugadas com o receio por parte da vítima de ser sujeita a várias avaliações e depoimentos, são alguns dos motivos explicativos da ausência de denúncias. Parece ser possível estabelecer um paralelismo entre a manutenção do abuso 
e a representação muito generalizada de que "não vai dar em nada", revelador de um sentimento de descrença na eficácia dos processos e na justiça.

Os resultados obtidos no nosso estudo revelam ainda coerência com o que literatura sustenta relativamente aos abusadores, metade é conhecida das vítimas e 1/4 a 1/3 são familiares da vítima. De acordo com Finkelhor e Ormrod (2001), dos detidos por abusos a crianças $48 \%$ vitimizaram um familiar ou conhecido. Wolfe e Birt (1997) revelam que embora exista na sociedade o estereótipo sobre a perigosidade dos estranhos, "em termos genéricos, podemos assumir que 10 a 30\% das vítimas são abusadas por desconhecidos, aproximadamente $40 \%$ são-no por pessoas próximas e os restantes $30 \%$ a $50 \%$ sê-lo-ão por elementos da própria família".

O conhecimento literário e diversos estudos sobre a temática têm corroborado a ideia que o abuso sexual está envolto em circunstâncias que dificultam a revelação. Furniss (1993) distingue cinco condições principais, designadamente o Síndrome de Segredo, a prova forense e a evidência médica que na maioria dos casos não são encontradas, as acusações verbais que devido à falta de evidência médica são essenciais à confirmação do abuso, a rejeição em acreditar nas tentativas de revelação por parte da criança (que começa na família e abrange igualmente os profissionais e o sistema legal), a mentira sob ameaça e as ansiedades referentes às consequências da revelação. De acordo com Carmo, Alberto e Guerra (2006) o abusador sexual não é apenas o agressor; integrado num contexto intrafamiliar, assume outros papéis, de pai, de cônjuge, sendo difícil para todos os envolvidos a separação dos diferentes interesses, particularmente para a criança, para a qual a reunificação da família é um dos interesses maiores. Torna-se extremamente dramático quando o abusador se constitui como o único recurso de subsistência e proteção.

Relativamente aos fatores de resolução do abuso sexual de crianças e no que concerne à necessidade de "informar a população em geral", este resultado remete-nos para a hipótese de que o "emergir" da problemática nos últimos anos tenha suscitado nos profissionais uma maior reflexão sobre como resolver a situação abusiva e a perceção da premência de implementação de programas que, podendo eventualmente ser focalizados nas crianças, deverão orientar-se para os pais, propondo ações com grupos profissionais e com a sociedade em geral de uma forma interativa (Fávero, 2003; Furniss, 1993; López, 1995).

Numa primeira análise das respostas dos sujeitos da amostra, estas mostram-se congruentes com a redutora explicação das situações abusivas focalizada nas características particulares do abusador e ancorada nas representações sociais construídas relativamente a este grupo e que usualmente conduzem ao que Furniss (1993) apelida de uma Intervenção Primária Punitiva centrada no abusador. Todavia, numa análise global dos 3 grupos de fatores, os resultados remetem para a abordagem sistémica/ ecológica, a mais consensual no seio da comunidade científica, apontando para a interação de fatores integrados em diferentes sistemas. A caracterização do abuso não se centra apenas na personalidade do abusador mas na interceção de várias condições.

Conforme sintetiza o Modelo das quatro pré condições de Finkelhor (1984), o desenvolvimento ontogénico do agressor (Belsky, 1980) não é, por si só, suficiente para o espoletar do abuso, sendo 
igualmente relevantes algumas características das figuras parentais, das organizações familiares, bem como do contexto sócio cultural.

A ponderação dos vários denominadores deverá sustentar o fluxograma interventivo que Furniss (1993) denomina de Intervenção Terapêutica Primária e que envolve todos os intervenientes. Esta intervenção deve abranger igualmente a comunidade e remete para a necessidade de um esforço de prevenção primário desejavelmente desenvolvido em parcerias, que objetive alterar mentalidades no que concerne à infância, à família, à autoridade e à vivência da sexualidade (Alberto 2000).

\section{Variáveis sócio-demográficas e representações sociais em torno do abuso sexual de crianças}

Considerando a variável sexo dos inquiridos, as diferenças encontradas indicam que esta variável implica diferenças significativas quanto ao grau de legitimação das situações abusivas, tendo-se verificado que as médicas e enfermeiras apresentam atitudes menos tolerantes que os seus pares do sexo masculino, sendo estes resultados congruentes com a maioria dos estudos que consideram que os profissionais do sexo feminino que lidam com estas problemáticas têm crenças atitudes e reações emocionais consideravelmente mais prosociais relativamente ao abuso sexual de crianças (Wellman, 1993). Poderá colocar-se a hipótese de que a atual construção de identidade de género ainda traduza uma menor tolerância ao abuso sexual de crianças por parte do sexo feminino dado a existência da ideia de que as crianças do sexo feminino são mais vítimas de abuso.

A tolerância ao abuso sexual de crianças mostrou também depender da categoria profissional, apontando no sentido de que profissionais médicos legitimaram mais o abuso sexual de crianças que os enfermeiros. Será lícito inferir que a diferença possa emergir de uma prática profissional de maior proximidade e continuidade na prestação de cuidados que compete aos enfermeiros e em particular aos enfermeiros dos CSP em relação aos médicos? Ou serão condicionantes de outra ordem, como eventualmente a diferente orientação curricular? Estas e outras hipóteses ficam a merecer explicação mais elaborada em futuros estudos.

No que concerne à experiência profissional em função dos anos de serviço, os resultados do estudo apontaram igualmente diferenças significativas na tolerância/legitimação ao abuso sexual de crianças, notando-se que os profissionais com maior número de anos de serviço legitimaram mais as situações abusivas. Esta constatação poderá fazer equacionar que a progressão nos anos de carreira, e o conhecimento e acompanhamento de processos tanto a nível profissional como social desenvolverão nestes profissionais uma desmotivação e descrença na intervenção bem como uma diferente sensibilidade para a problemática, que os distingue a nível das representações. Torna-se pertinente um melhor esclarecimento desta questão em futuros estudos.

Relativamente à idade, os resultados indicaram que os médicos e os enfermeiros com mais idade apresentam maior legitimação do abuso sexual de crianças. Tendo em conta que estes profissionais médicos e enfermeiros cresceram e receberam a sua educação pessoal num contexto sociocultural diferente onde eram vigentes estereótipos como o da fantasia infantil, da culpabilização dos adolescentes, e da criança sedutora, poderão mais facilmente aceitar estes registos. A menor legitimação por parte dos profissionais 
das outras categorias etárias poderá decorrer de uma diferente formação social e profissional e/ou do facto da permanente exposição a constantes mensagens pejorativas acerca do abuso sexual de crianças.

Existindo na análise realizada um efeito determinante do sexo, tivemos o cuidado de efetuar testes adicionais para perceber as diferenças registadas tendo constatado que ao analisar a influência sexo-idade as médicas e enfermeiras entre os 51 e os 64 anos são mais tolerantes ao abuso sexual de crianças, facto que deverá ser equacionado em futuras investigações.

O presente estudo não encontrou influência de variáveis como o estado civil, a existência de filhos, o grau das habilitações académicas, a experiência prévia com crianças vítimas de ASC, e a entidade de referência de ASC nas representações dos médicos e enfermeiros dos CSP quanto ao ASC. No que concerne à área geo-demográfica, a maior proximidade contextual que é expectável nos profissionais dos CSP que exercem a sua atividade em centros de saúde de áreas rurais permitia equacionar que se pudessem distinguir ao nível das representações das situações abusivas, podendo a ausência de diferenças estar relacionada com o facto da atual globalização da informação tender a uniformizar os contextos socioculturais.

A análise efetuada permitiu concluir que, relativamente à informação/formação para identificar ou para intervir em casos de ASC e às fontes de informação sobre a problemática, estas variáveis também não demonstraram a distinção destes profissionais relativamente às representações das situações abusivas. Estes resultados podem sugerir a influência da permeabilidade destes profissionais à informação veiculada através dos media acerca desta problemática.

\section{Limitações do estudo e sugestões para futuras investigações}

De um modo geral, os objetivos deste estudo foram cumpridos, na medida em que assumimos tratar-se de um estudo de cariz exploratório. Tratando-se de um primeiro estudo em psiquiatria cultural em Portugal, sobre representações sociais em torno do abuso sexual de crianças numa população de médicos e de enfermeiros dos CSP, parece pertinente mencionar algumas limitações do presente estudo passíveis de serem colmatadas em futuras investigações.

O fato da amostra ser de conveniência faz com que esteja circunscrita a profissionais dos Cuidados de Saúde Primários da zona centro do país e constituir-se-ia relevante abranger outras regiões do país, mormente estudar a influência das assimetrias entre o litoral e o interior do país. Por outro lado, seria adequado recolher uma amostra com uma distribuição mais representativa de homens e mulheres na classe profissional médica e de enfermagem, uma vez que neste estudo os sujeitos do sexo feminino são aproximadamente o quádruplo dos sujeitos do sexo masculino.

É igualmente de ter em conta que a desejabilidade social e profissional poderá ter influenciado as respostas dos sujeitos, uma vez que o abuso sexual de criança é um fenómeno socialmente reprovado.

Como recomendações para futuras investigações, sugere-se que o protocolo seja aplicado a uma amostra maior de profissionais médicos e enfermeiros dos cuidados de saúde primários, abrangendo mais áreas do país e com uma distribuição que represente mais adequadamente a classe médica e de enfermagem, superando as limitações anteriormente citadas. 
Sendo esta uma problemática transversal a diversas áreas pareceria igualmente pertinente um estudo multidisciplinar, que inclua outros profissionais com contacto privilegiado com crianças e que possam ter um papel interventivo nesta temática (e.g. médicos e enfermeiros dos cuidados secundários na medida em que a problemática interessa a todas as disciplinas médicas, professores, assistentes sociais, agentes policiais, jornalistas, psicólogos, juristas), assim como seria igualmente pertinente um estudo que englobasse a população em geral.

Pela nossa parte fica-nos no entanto a sensação de uma certa incompletude que a própria temática proporciona e a vontade de colmatar algumas das limitações supracitadas, talvez num trabalho pluridisciplinar e multifatorial, que correlacione a medicina e o direito, e permita compreender e adequar o papel efetivo destas duas áreas naquela que consideramos ser a melhor resolução desta problemática-a prevenção.

\section{Conclusões}

A problemática do abuso sexual de crianças emergiu nos últimos anos, "rompendo" o silêncio social (López, 1995), adquirindo uma crescente visibilidade e provocando simultaneamente um aumento de reprovação e de preocupação com o fenómeno. No entanto, este despertar social espelhado no aumento da investigação e no constante enfoque por parte dos media, não conseguiu ainda levantar o manto de secretismo e de inibições em que a problemática do abuso sexual infantil continua envolta. Talvez por nos confrontar com o lado mais ignóbil do ser humano, continuemos apenas a vislumbrar a ínfima parte de um todo.

Muitas teorias têm emergido para a compreensão da complexidade e dinâmica que envolve o fenómeno do abuso sexual de crianças. Um denominador comum a todas as teorias é a importância fulcral do papel dos intervenientes mais diretos nas situações do abuso sexual de crianças. Numa visão sistémica trata-se duma realidade multidimensional, uma construção social partilhada por um coletivo, em que a realidade e o discurso se constroem recursivamente implicando a necessidade de multiplicar os "olhares" sobre a realidade.

O papel da sociedade e de alguns grupos profissionais, pela influência direta das representações sociais em torno do abuso sexual de crianças, reveste-se de capital importância na sua investigação e intervenção.

Os profissionais de saúde e, em particular, os médicos e enfermeiros dos CSP constituem grupos profissionais em posição privilegiada relativamente à proteção da criança e são intervenientes determinantes nesta problemática. Torna-se, então, fundamental perceber os seus discursos, os significados que atribuem aos comportamentos, conhecer os modelos de leitura e as suas próprias ressonâncias sobre a temática.

Intentando perspetivar as representações sociais em torno do abuso sexual de crianças, o presente estudo identificou as representações sociais que médicos e enfermeiros dos cuidados de saúde primários detêm sobre esta problemática. Procurou conhecer as dimensões do abuso sexual mais suscetíveis de serem legitimadas pelos nossos sujeitos e quais as atribuições que estes profissionais têm sobre os fatores facilitadores, os fatores de manutenção e os fatores de resolução de situações abusivas. Foi 
analisada a influência de variáveis sócio-demográficas sobre essas representações, nomeadamente o sexo, a categoria profissional, a idade, a existência de filhos dos sujeitos, a experiência profissional em tempo de serviço e contacto com situações de abuso sexual de crianças. Foi ainda ponderada a influência da entidade de referenciação de casos suspeitos de ASC, da informação/formação na identificação e no modo de intervenção em casos de ASC e ainda das fontes de informação/formação que são recurso para estes profissionais, nas respostas aos instrumentos do protocolo de investigação.

Com este estudo pode concluir-se que os instrumentos desenvolvidos para análise das representações sociais em torno do abuso sexual de crianças, o Questionário sobre abuso sexual de crianças - Histórias (QRASC-HIS), e o Questionário sobre abuso sexual de crianças fatores Facilitadores, de Manutenção e Resolução (QASCFMR) apresentam qualidades psicométricas a nível da consistência interna e da validade concorrente que os constituem bons instrumentos de investigação a utilizar nesta temática.

Os resultados obtidos permitiram concluir que médicos e enfermeiros dos Cuidados de Saúde Primários apresentam valores pouco legitimadores para o abuso sexual de crianças.

Quanto à avaliação dos fatores promotores, de manutenção e de resolução os que apresentaram respetivamente maior concordância foram os "antecedentes de violência na família do abusador"; "as ameaças por parte do abusador"; e "informar a população em geral sobre a problemática do abuso sexual de crianças" e "dar apoio à vítima para que ela adquira competências de impedir o abuso".

A existência de filhos, a área do centro de saúde onde exerce a profissão e a experiência profissional prévia com crianças vítimas de ASC não evidenciaram diferenças significativas no grau de tolerância destes profissionais sobre este tipo de maltrato.

Relativamente ao tipo de entidade a quem referenciam casos de ASC, constatou-se curiosamente que só uma ínfima percentagem denuncia à Policia Judiciária, e que o tipo de entidade de referenciação não interfere na tolerância destes profissionais em relação ao ASC.

A informação/formação destes profissionais quer para identificar quer para intervir em situações de abuso sexual infantil demonstrou igualmente não condicionar a sua legitimação relativamente ao ASC.

Os médicos e enfermeiros do sexo masculino legitimaram mais do que os do sexo feminino; e os médicos de ambos os sexos legitimaram mais do que os enfermeiros. No que diz respeito à idade, constatou-se que as médicas e as enfermeiras com o avançar da idade, legitimavam mais, o sexo feminino, à medida que avança na idade, enquadra mais as situações abusivas em vivências "normativas", ignorando a dimensão sexual envolvida. Quanto aos respondentes do sexo masculino constatou-se que os homens com idade compreendida entre os 30 e os 40 anos são os demonstraram menos tolerância para com as situações abusivas.

O nosso estudo revelou existir uma relação entre o tempo de experiência profissional e a legitimação do abuso sexual de crianças com os profissionais a mostrarem mais tolerância ao ASC com o avançar dos anos de serviço.

Concluindo, este estudo revelou que as representações sociais dos médicos e enfermeiros dos CSP em torno do abuso sexual de crianças se revestem de capital importância, para que possam "fazer a diferença" e não sejam veículos de discursos sociais deturpados e estereotipados, disfarçados 
de linguagem científica que potenciam a invisibilidade e impunidade do fenómeno e impedem a implementação de adequadas medidas de prevenção, revelando necessidade de que colocando esta problemática na sua agenda de prioridades, através intervenções técnicas concretas e abordagens sustentadas nos direitos da criança se assumam como profissionais com uma intervenção evidente e eficaz na proteção das crianças e adolescentes vítimas de abuso sexual.

\section{Bibliografia}

Alberto, I. (2000). As consequências do abuso sexual infantil: Contributo dos estudos longitudinals. Psychologica, 24, 119-127.

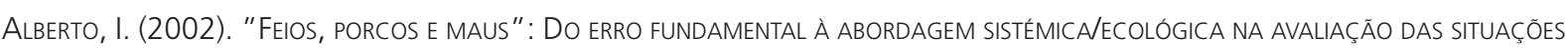
de ABuso seXual. PSyCholog/CA, 30, 69-77.

Alberto, I. (2006). Maltrato e trauma na infância. Coimbra: Almedina.

Almeida, A., André, I., \& Almeida, H. (2001). famillas e maus-tratos às crianças em Portugal. Lisboa: ed. Assembleia da REPÚBLICA.

Almeida, C., \& Vilalonga, J. (2007). Código Penal. Coimbra: Almedina.

AzeVedo, M., \& Guerra, V. (orgs.). (1993). InfânCia e Violência Doméstica: Fronteiras do Conhecimento. S. Paulo: Ed. Cortez. Belsky, J. (1980). Child Maltreatment: An ecological integration. American Psychologist, 35, 320-335.

Carmo, R., Alberto, I., Guerra, P. (2006). O Abuso Sexual de Menores. Uma Conversa sobre Justiça entre o Direito e a Psicologia. Coimbra: Almedina.

Favero, M. (2003). Sexualidade infantill e abusos sexuais a Menores. Lisboa. Climepsi

Finkelhor, D. (1979). Sexualy Victimized Children. New York. The Free Press.

Finkelhor, D. (1984). Chill sexual abuse: New theory and research (pp.107-133). New York: Free Press.

FinkelHor, D., \& Douglas, E. Childhood SeXual Abuse FaCt Sheet hTtP.//Www.unh.EDu/cCrC/FACTSheEt/PdF/CSA-FS20.pDF Cons EM 20-10-2010

Finkelhor, D. (1986). A sourcebook on chilld sexual abuse. Newbuy Park, CA: Sage Publications.

Finkelhor, D. (1994). The international epidemiology of Child seXual abuse. Child Abuse \& Neglect, 18 (5) 409-417.

Finkelhor, D. (1994). Current Information on Scope and Nature of Child Sexual Abuse. Future of Chilldren, 4 (2), $31-53$.

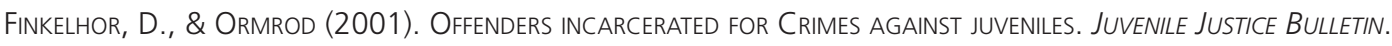

HTTP.//WWW.UNH.EDU/CCRC/FACTSHEET/PDF/CSA-FS20.PDF CONS EM 20-10-2010

Finkelhor, D. (2009). The Prevention of Sexual Abuse. The Future of Children, 19, (2), 169-194.

Furniss, T. (1993). Abuso Sexual da Criança. Uma abordagem multidisciplinar. Porto Alegre: Artes médicas.

Furniss, T. (2008). Resumo de ComunicaÇão em Seminário de Formação sobre "Abuso SeXual de Crianças: Aspetos específicos na terapia Individual e no Trabalho Familiar". Lisboa 6,7e 8 de Março de 2008.

Furniss, T. (2008). Resumo de Comunicação em Seminário de Formação sobre "Abuso Sexual de Crianças: O Trabalho com as mães Aspetos específicos do Trabalho com Rapazes Abusados Sexualmente" Lisboa 29,30 e 31 de Malo de 2008.

Furniss, T. (2008). Resumo de Comunicação em Seminário de Formaçāo sobre Seminário de FormaÇão "Abusadores SeXuals de CRIANÇAS: PORQUe É QUE ABUSAM E QUAIS AS ESTRATÉGIAS UTILIZADAS NO ABUSO SEXUAL DE CRIANÇAS?". LISBOA 2,3 E 4 de OUTUBRO de 2008.

Furniss, T. (2010). Resumo de Comunicação em Seminário de Formação sobre "Abusadores Sexual de Crianças: Rapazes

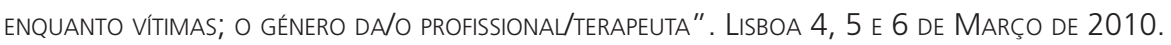


Furniss, T. (2010). Resumo de Comunicação em Seminário de Formação sobre "Compreender o processo do Abuso Sexual de CRIANÇAS: COMO UMA PRÉ CONDIÇÃO PARA O TRABALHO COM AS VÍTIMAS E COM OS ABUSADORES SEXUAIS: CRIANÇAS COM COMPORTAMENTOS SEXUAIS DE TRANSGRESSÃO; JOVENS ABUSADORES SEXUAIS". LISBOA 21,22 E 23 de OUtUBRO dE 2010 em LisBoA.

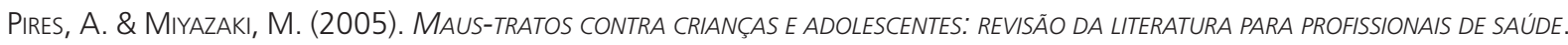
Artigo de revisão. Faculdade de Medicina de São José do Rio Preto.

Konker, C. (1992). Rethinking Child Sexual Abuse: An Anthropological Perspective. Washington: University of Washington.

Lawson, C. (1993). Mother-son sexual abuse: rare or underreported? A critique of the research. Child Abuse and Neglect, $17,409-421$.

Leyens, J. (1985). Teorias de personalidade na dinÂmica social. Lisboa: Bibloteca Verbo de Psicologia e CiênCias Humanas.

lópez, F. (1995). Prevencion de los abusos Sexuales de Menores y Educacion Sexual. Salamanca: Amaurú Edicions.

Machado, C., Gonçalves, R., \& Matos, M. (2000). Escalas para aValiação do enquadramento cultural da VIolênCia contra MULHERES E CRIANÇAS. BRAGA: UNIVERSIDADE DO MINHO.

Machado, C., \& Gonçalves, R. (2002). Violência e Vittmas de Crimes. (vol.2: criançAs). Coimbra. Quarteto.

Machado, C. (2010). Novas Formas de Vitimação criminal. Braga: Psiquilibrios Edições.

MCKenNa, K., (2003). THE ECONOMIC COSTS AND CONSEQUENCES OF CHILD ABUSE IN CANADA. UniveRSITY OF WeSTERN ONTÁRIO.

HTTP://DSP-PSD.PWGSC.GC.CA/COLLECTION_2007/ICC-CDC/JL2-39-2003.PDF_CONSULTADO EM 20-09-10

Magaliães, T. (2005). Maus Tratos em Crianças e Jovens. Coimbra: Quarteto.

HTTP://REPOSITORIUM.SDUM.UMINHO.PT_CONSULTADO EM 17-08-10

Maroco, J. (2007). Análise Estatística com a utilzação do SPSS. 3a Ed. Lisboa: Ed. Sílabo.

MoscovicI, S. (1961). La PSYCHANALYSE, SON IMAGE ET SON PUBLIC. PARIS: PUF

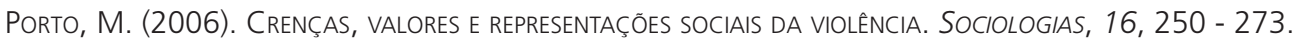

Quartillo, M. (2001). Cultura, Medicina e Psiquiatria. Coimbra: ed. Quarteto.

Querido, A. (2009) Representações socials em torno do Abuso Sexual de Crianças. Dissertação de Mestrado em Ciências da Educação. Coimbra. Universidade de Coimbra. Faculdade de Psicologia e CiênCias de Educação.

Salter, A. (1988). Treating Child Sexual Offenders and Victims. Newbury Park, CA:Sage.

HTTP://WWW.SLD.CU/GALERIAS/PDF/SITIOS/PREVEMI/MI_COLOMBIA.PDF. CONSULTADO EM 10-06-10

Wellman, M. (1993). Child Sexual Abuse and gender differences: attitudes and prevalence. Child Abuse \& Neglect, 17,(4), 539-547

HTTP://WWW.CRCVC.CA/DOCS/CHILD_ABUSE.PDF CONSULTADO EM 10-06-10 